\title{
Cyclopolymerization XXIX. Radical Polymerizations of $N$-Methyl- $N$-(meth)allyl-2-(t-butoxycarbonyl)allylamines: Effect of a Bulky Ester Group on Cyclopolymerizability of 1,6-Dienes with Functional Groups of No Homopolymerization Tendencies
}

\author{
Toshiyuki KodaIRA, ${ }^{\dagger}$ Masahiko Satoyama, Michio UrushisaKi, and Tamotsu Hashimoto
}

Department of Materials Science and Engineering, Faculty of Engineering, Fukui University, Fukui 910-8507, Japan

(Received June 7, 2000; Accepted August 16, 2000)

\begin{abstract}
Cyclopolymerizations of $N$-methyl- $N$-allyl-2-( $t$-butoxycarbonyl)allylamine (1a) and $N$-methyl- $N$ methallyl-2-( $t$-butoxycarbonyl)allylamine (1b) were undertaken to see the effect of a bulky ester $t$-butyl group on the cyclopolymerizabilities of $N$-substituted $N$-(meth)allyl-2-(alkoxycarbonyl)allylamines by comparing with those of $N$ methyl- $N$-(meth)allyl-2-(methoxycarbonyl)allylamine (2) and $N$-t-butyl- $N$-(meth)allyl-2-(methoxycarbonyl)allylamine (3). Non-homopolymerizability of the monofunctional counterparts of $\alpha$-substituted acryloyl groups of $1 \mathbf{a}$ and $1 \mathbf{b}$ was confirmed. Polymerizability of $1 \mathbf{a}$ was almost similar to that of $\mathbf{2}$ with an $N$-allyl group and $\mathbf{1 b}$ polymerized faster than 2 with an $N$-methallyl group despite the fact that conjugative nature of the $\alpha$-substituted acryloyl groups of 1 are less effective as compared with those of 2 . The results were interpreted by assuming that steric effect of the bulky substituent influences more strongly on retarding termination rates than propagation rates of these monomers. Degrees of cyclization of poly(1a) and poly(1b) were found to be $100 \%$ and $96 \%$, respectively. This indicates that the bulky ester $t$-butyl group influences the cyclopolymerizabilities of these 1,6-dienes in essentially different manner from those of the bulky $N$-substituent and we can design 1,6-dienes with both high cyclization and polymerization tendencies by introducing bulky group into proper position of these molecules. Repeat cyclic units of poly(1a) and poly(1) $)$ were assigned to fiveand six-membered rings, respectively.
\end{abstract}

KEY WORDS Radical Cyclopolymerization / 1,6-Diene / $\alpha$-Substituted Acryloyl Group / Repeat Cyclic Unit / Degree of Cyclization / Bulky Substituent /

Bulky substituents occasionally influence significantly polymerization behavior of various monomers apparently in a different manner from what is expected from their steric hindrance. For example, enhancement of overall polymerization rates for the monomers with a bulky group has often been reported as compared with those with a small substituent such as a methyl group. ${ }^{1,2}$ Enhancement of cyclization tendencies of 1,6-dienes that were introduced with a $t$-butyl group is one of the most well-known substituent effect on cyclopolymerizations. ${ }^{3,4}$ In connection with these results, polymerization behavior of $N$-methyl- $N$-allyl-2-( $t$-butoxycarbonyl)allylamine (1a) and $N$-methyl- $N$-methallyl-2-( $t$-butoxycarbonyl)allylamine (1b) (see Scheme 1) was investigated for the purpose to see how their cyclopolymerizabilities are changed from their analogues with a small methoxycarbonyl group. We have already reported the cyclopolymerizations of $N$-methyl- $N$-(meth) allyl-2(methoxycarbonyl)allylamines $(2)^{5,6}$ and $N$-t-butyl- $N$ (meth)allyl-2-(methoxycarbonyl)allylamines (3) (see scheme 1). ${ }^{7,8}$ They were polymerized to show the validity of our proposal that the use of functional groups with a higher conjugative nature together with no homopolymerization tendencies is essential for the design of 1,6dienes with not only a high cyclization tendency but also high polymerizability. ${ }^{5}$ This is because $\alpha$-substituted acryloyl groups of these dienes do not homopolymerize despite their high conjugative nature, when they exists

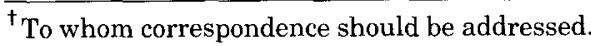<smiles>[R]C(=C)CN([R])CC(=C)C(=O)O[Na]</smiles>

$1,2,3$

\begin{tabular}{c|ccc} 
1, 2,3 & $\mathrm{R}_{1}$ & $\mathrm{R}_{2}$ & $\mathrm{R}_{3}$ \\
\hline 1a & $\mathrm{H}$ & $\mathrm{CH}_{3}$ & $\mathrm{C}\left(\mathrm{CH}_{3}\right)_{3}$ \\
1b & $\mathrm{CH}_{3}$ & $\mathrm{CH}_{3}$ & $\mathrm{C}\left(\mathrm{CH}_{3}\right)_{3}$ \\
2a & $\mathrm{H}$ & $\mathrm{CH}_{3}$ & $\mathrm{CH}_{3}$ \\
2b & $\mathrm{CH}_{3}$ & $\mathrm{CH}_{3}$ & $\mathrm{CH}_{3}$ \\
3a & $\mathrm{H}$ & $\mathrm{C}\left(\mathrm{CH}_{3}\right)_{3}$ & $\mathrm{CH}_{3}$ \\
3b & $\mathrm{CH}_{3}$ & $\mathrm{C}\left(\mathrm{CH}_{3}\right)_{3}$ & $\mathrm{CH}_{3}$
\end{tabular}

Scheme 1 .

as monoene compounds. Enhancement of cyclization tendency by a bulky $N$-t -butyl group was also observed in these monomers, since completely cyclized polymers were obtained from $\mathbf{3 b}$ though $\mathbf{2 b}$ yielded polymers with a small amount of pendant unsaturations. ${ }^{6,8}$ It was found that the conjugative nature of the $\alpha$-substituted acryloyl groups of $\mathbf{2}$ and $\mathbf{3}$ decreased with the bulkiness of the $N$-substituents and it could be correlated with the polymerizabilities of these monomers. This means that a bulky $N$ - $t$-butyl group decreases the polymerizabilities of 2 and 3. In the case of ether dimers of $\alpha$-hydroxymethyl acrylates, their acryloyl groups with a bulky ester alkyl group conjugate less effectively. ${ }^{9}$ However, their polymerizabilities along with the cyclization tendencies increased with the bulkiness of their ester alkyl group. This suggests that we might be able to obtain 1,6-dienes with both high polymerizabilities and high cyclization 
Effect of a Bulky Substituent on Cyclopolymerization

Table I. Boiling points and elementary analysis

\begin{tabular}{|c|c|c|c|c|c|c|c|}
\hline \multirow{2}{*}{ Monomer } & \multirow{2}{*}{$\frac{\mathrm{bp}^{\mathrm{a}}}{{ }^{\circ} \mathrm{C} \mathrm{mmHg}{ }^{-1}}$} & \multicolumn{2}{|c|}{$\mathrm{C} / \%$} & \multicolumn{2}{|c|}{$\mathrm{H} / \%$} & \multicolumn{2}{|c|}{$\mathrm{N} / \%$} \\
\hline & & Calcd & Found & Calcd & Found & Calcd & Found \\
\hline $1 a^{b}$ & $50 / 0.3$ & 68.19 & 67.94 & 10.03 & 10.28 & 6.63 & 6.36 \\
\hline $4 a^{c}$ & $55 / 0.6$ & 67.55 & 67.26 & 10.88 & 11.14 & 6.57 & 6.35 \\
\hline $1 b^{d}$ & $64 / 0.6$ & 69.28 & 69.08 & 10.30 & 10.54 & 6.22 & 6.06 \\
\hline $4 b^{c}$ & $58 / 0.4$ & 68.66 & 68.80 & 11.10 & 11.30 & 6.16 & 6.05 \\
\hline
\end{tabular}

${ }^{\mathrm{a}}$ Not corrected. ${ }^{\mathrm{b}} N$-Methyl- $N$-allyl-2-( $t$-butoxycarbonyl)allylamine. ${ }^{\mathrm{c}} N$-Methyl- $N$-propyl-2-( $t$-butoxycarbonyl)allylamine ${ }^{\mathrm{d}} N$-Methyl- $N$ methallyl-2-( $t$-butoxycarbonyl)allylamine ${ }^{e} N$-Methyl- $N$-isobutyl-2-( $t$-butoxycarbonyl)allylamine.

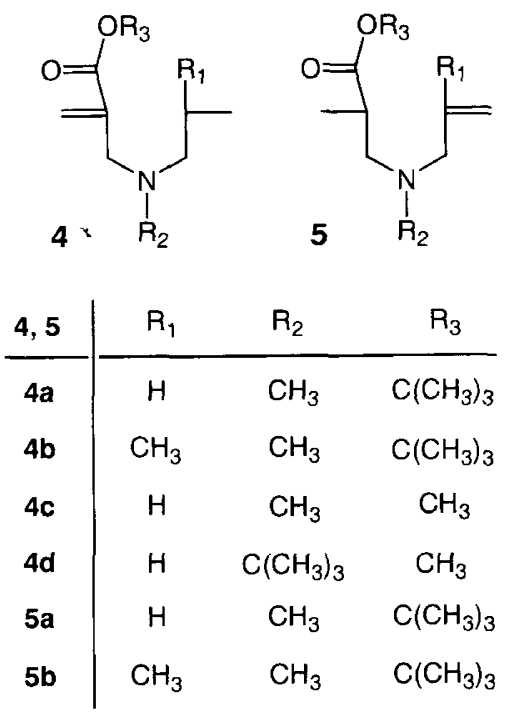

Scheme 2.

tendencies by introducing a bulky $t$-butyl group instead of a methyl group into the ester group of 2 , which is our purpose of this series of investigations on cyclopolymerization.

Polymerizations of $N$-methyl- $N$-propyl-2-( $t$-butoxycarbonyl)allylamine (4a) and $N$-methyl- $N$-isobutyl-2-( $t$ butoxycarbonyl)allylamine (4b) (see Scheme 2) were also undertaken, though no-homopolymerizability of $\mathrm{N}$ substituted- $N$-propyl-2-(methoxycarbonyl) allylamines (4c and $4 d$ ) which have similar structures to $4 \mathbf{a}$ and $4 \mathbf{b}$ has already been confirmed. ${ }^{5,7}$ This is because bulky $t$ butyl group introduced in $\mathbf{4 a}$ and $\mathbf{4 b}$ might influence polymerization behavior of these compounds in an unexpected manner and yield high polymers.

\section{EXPERIMENTAL}

\section{Materials}

Monomers 1 , $\mathbf{4 a}$, and $\mathbf{4 b}$ were synthesized by the equimolar reaction between $t$-butyl $\alpha$-(bromomethyl)acrylate (BMA) and corresponding amines based on the procedure for the preparation of $\mathbf{2 a} .^{5}$ Crude products obtained were subjected to repeated distillations to give pure liquids. Yields of the final stage of the synthesis of these monomers were from 40 to $60 \%$ after distillations two times. The supposed structures were confirmed by elementary analyses and nuclear magnetic resonance (NMR) spectra. The boiling points (bp) and results of the elementary analyses are shown in Table I. Chemical shifts of the characteristic absorption peaks of ${ }^{1} \mathrm{H}$ and ${ }^{13} \mathrm{C}$ NMR spectra of $\mathbf{1}, \mathbf{4 a}$, and $\mathbf{4 b}$ are as follow. ${ }^{1} \mathrm{H}$ NMR for $1 \mathrm{a}: \delta=6.16(\mathrm{~s}, 1 \mathrm{H}), 5.85(\mathrm{~m}, 1 \mathrm{H}), 5.69(\mathrm{~s}, 1 \mathrm{H}), 5.14(\mathrm{t}$, $2 \mathrm{H}), 3.16(\mathrm{~s}, 2 \mathrm{H}), 3.02(\mathrm{~d}, 2 \mathrm{H}), 2.21(\mathrm{~s}, 3 \mathrm{H})$, and $1.50(\mathrm{~s}, 9$ $\mathrm{H}) \mathrm{ppm} .{ }^{13} \mathrm{C}$ NMR for $1 \mathrm{a}: \delta=166.3(>\mathrm{C}=\mathrm{O}), 139.3\left(\mathrm{CH}_{2}\right.$ $=C<$, acryloyl $), 135.9\left(\mathrm{CH}_{2}=\mathrm{CH}-\right.$, allyl $), 125.5\left(\mathrm{CH}_{2}=\right.$ $\mathrm{C}<$, acryloyl $), 117.2\left(\mathrm{CH}_{2}=\mathrm{CH}^{-}\right.$, allyl $), 80.6\left(-\mathrm{O}^{-} \mathrm{C}\right.$ $\left.\left(\mathrm{CH}_{3}\right)_{3}\right), 60.6\left(>\mathrm{N}-\mathrm{CH}_{2}-\right), 57.2\left(>\mathrm{N}-\mathrm{CH}_{2}-\right), 42.4(>\mathrm{N}-$ $\left.\mathrm{CH}_{3}\right)$, and $28.1\left(-\mathrm{C}\left(\mathrm{CH}_{3}\right)_{3}\right) \mathrm{ppm} .{ }^{1} \mathrm{H} \mathrm{NMR}$ for $\mathbf{1 b}: \delta=6.14$ $(\mathrm{s}, 1 \mathrm{H}), 5.70(\mathrm{~s}, 1 \mathrm{H}), 4.87(\mathrm{~s}, 1 \mathrm{H}), 4.82(\mathrm{~s}, 1 \mathrm{H}), 3.11(\mathrm{~s}$, $2 \mathrm{H}), 2.88(\mathrm{~s}, 2 \mathrm{H}), 2.15(\mathrm{~s}, 3 \mathrm{H}), 1.73(\mathrm{~s}, 3 \mathrm{H})$, and $1.49 \mathrm{ppm}$ (s, 9H). ${ }^{13} \mathrm{C}$ NMR for $1 \mathrm{~b}: \delta=166.4(>\mathrm{C}=\mathrm{O}), 143.8\left(\mathrm{CH}_{2}\right.$ $\left.=C\left(\mathrm{CH}_{3}\right)^{-}\right), 139.7\left(\mathrm{CH}_{2}=C<\right.$, acryloyl $), 124.9\left(\mathrm{CH}_{2}=\mathrm{C}\right.$ $<$, acryloyl), $112.5\left(\mathrm{CH}_{2}=\mathrm{C}\left(\mathrm{CH}_{3}\right)^{-}\right), 80.5\left(-\mathrm{O}-\mathrm{C}\left(\mathrm{CH}_{3}\right)_{3}\right)$, $64.5\left(>\mathrm{N}-\mathrm{CH}_{2}-\right), 57.7\left(>\mathrm{N}-\mathrm{CH}_{2}-\right), 42.2\left(>\mathrm{N}-\mathrm{CH}_{3}\right), 28.1$ $\left(-\mathrm{C}\left(\mathrm{CH}_{3}\right)_{3}\right)$, and $20.6\left(\mathrm{CH}_{2}=\mathrm{C}\left(\mathrm{CH}_{3}\right)^{-}\right) \mathrm{ppm} .{ }^{1} \mathrm{H}$ NMR for $4 \mathrm{a}: \delta=6.14(\mathrm{~s}, 1 \mathrm{H}), 5.66(\mathrm{~s}, \mathrm{H}), 3.14(\mathrm{~s}, 2 \mathrm{H}), 2.28(\mathrm{t}, 2 \mathrm{H})$, $2.20(\mathrm{~s}, 3 \mathrm{H}), 1.49$ (sextet, $1 \mathrm{H}), 1.49(\mathrm{~s}, 9 \mathrm{H})$, and $0.88 \mathrm{ppm}$ $(\mathrm{t}, 3 \mathrm{H}) .{ }^{13} \mathrm{C} \mathrm{NMR}$ for $4 \mathrm{a}: \delta=166.5(>\mathrm{C}=\mathrm{O}), 139.6\left(\mathrm{CH}_{2}=\right.$ $C<$, acryloyl), $125.2\left(\mathrm{CH}_{2}=\mathrm{C}<\right.$, acryloyl), $80.5(-\mathrm{O}-\mathrm{C}$ $\left.\left(\mathrm{CH}_{3}\right)_{3}\right), 59.6\left(>\mathrm{N}-\mathrm{CH}_{2}-\right), 58.0\left(>\mathrm{N}-\mathrm{CH}_{2}-\right), 42.3(>\mathrm{N}-$ $\left.\mathrm{CH}_{3}\right), 28.1\left(-\mathrm{C}\left(\mathrm{CH}_{3}\right)_{3}\right), 20.7\left(-\mathrm{CH}_{2} \mathrm{CH}_{2} \mathrm{CH}_{3}\right)$, and 11.8 ($\mathrm{CH}_{2} \mathrm{CH}_{2} \mathrm{CH}_{3}$ ) ppm. ${ }^{1} \mathrm{H}$ NMR for $4 \mathbf{b}: \delta=6.11(\mathrm{~s}, 1 \mathrm{H}), 5.67$ $(\mathrm{s}, 1 \mathrm{H}), 3.11(\mathrm{~s}, 2 \mathrm{H}), 2.17(\mathrm{~s}, 3 \mathrm{H}), 2.08(\mathrm{~d}, 2 \mathrm{H}), 1.56(\mathrm{~m}$, $1 \mathrm{H}), 1.49(\mathrm{~s}, 9 \mathrm{H})$, and $0.88 \mathrm{ppm}(\mathrm{d}, 6 \mathrm{H}) .{ }^{13} \mathrm{C} \mathrm{NMR}$ for $4 \mathrm{~b}: \delta$ $=166.6(>\mathrm{C}=\mathrm{O}), 139.9\left(\mathrm{CH}_{2}=C<\right.$, acryloyl $), 124.9$ $\left(C \mathrm{H}_{2}=\mathrm{C}<\right.$, acryloyl), $80.4\left(-\mathrm{O}-\mathrm{C}\left(\mathrm{CH}_{3}\right)_{3}\right), 66.1(>\mathrm{N}-$ $\left.\mathrm{CH}_{2}-\right), 58.7\left(>\mathrm{N}-\mathrm{CH}_{2}-\right), 42.6\left(>\mathrm{N}-\mathrm{CH}_{3}\right), 28.1 \quad(-\mathrm{C}$ $\left.\left(\mathrm{CH}_{3}\right)_{3}\right), 26.3\left(-\mathrm{CH}\left(\mathrm{CH}_{3}\right)_{2}\right)$, and $20.8\left(-\mathrm{CH}\left(\mathrm{CH}_{3}\right)_{2}\right)$ ppm.

BMA $^{10}$ was prepared by the reported procedure. $N$ Methylallylamine and $N$-methylmethallylamine were synthesized according to the synthetic procedure for the former. ${ }^{11}$

Commercial 2,2'-azobisisobutyronitrile (AIBN) was recrystallized from ethyl alcohol. All common solvents were purified by the usual methods.

\section{Polymerization}

Polymerizations were performed in sealed tubes. Given amount of monomer, initiator, and solvent (in case of solution polymerizations) were placed in glass ampoules, which were then subjected to several freezepump-thaw cycles and sealed. After polymerization in a constant-temperature bath, the polymerization mixture was poured into a large amount of petroleum ether. The polymers were reprecipitated from benzene solution into petroleum ether to obtain pure polymers for measurements. Conversions were determined from the residual monomer concentration measured by gas chromatography (GC) with tetralin as the internal standard, since some portion of their polymers was found to be soluble in petroleum ether. 
Table II. Polymerizations of $1,4 \mathbf{a}, \mathbf{4 b}$, and related compounds at $60^{\circ} \mathrm{C}$ in bulk

\begin{tabular}{|c|c|c|c|c|c|c|c|c|}
\hline \multirow{2}{*}{ No. } & \multirow{2}{*}{ Monomer } & {$[\mathrm{AIBN}]_{0}$} & Time & $\mathrm{DC}^{\mathrm{a}}$ & {$[\eta]$} & \multirow{2}{*}{$M_{\mathrm{n}}$} & \multirow{2}{*}{$M_{\mathrm{w}} / M_{\mathrm{n}}$} & \multirow{2}{*}{$\begin{array}{c}\text { Conv } \\
\%\end{array}$} \\
\hline & & $M \times 10^{3}$ & $\mathrm{~h}$ & $\%$ & $\mathrm{dL} \mathrm{g}^{-1}$ & & & \\
\hline 1 & $1 \mathbf{a}$ & 6.06 & 0.7 & 100 & & & & 12 \\
\hline 2 & $1 \mathbf{a}$ & 6.06 & 2 & 100 & 0.24 & & & 44 \\
\hline 3 & $\mathbf{1 a}$ & 6.06 & 4 & 100 & 0.24 & & & 74 \\
\hline 4 & $1 \mathbf{a}$ & 6.06 & 8 & 100 & & & & 82 \\
\hline 5 & $4 \mathbf{a}$ & 112 & 24 & & & & & 0 \\
\hline $6^{\mathrm{b}}$ & $\mathbf{2 a}$ & 6.06 & 0.3 & 100 & 0.24 & & & 7 \\
\hline $7^{\mathrm{b}}$ & $2 \mathbf{a}$ & 6.06 & 0.7 & 100 & 0.28 & & & 20 \\
\hline $8^{c}$ & $\mathbf{3 a}$ & 28.0 & 2 & 100 & & & & 45 \\
\hline $9^{c}$ & $\mathbf{3 a}$ & 28.0 & 4 & 100 & 0.16 & & & 78 \\
\hline 10 & $1 b$ & 28.0 & 0.2 & 96 & & & & 6 \\
\hline 11 & $1 \mathbf{b}$ & 28.0 & 1 & & & 78000 & 2.2 & 38 \\
\hline 12 & $\mathbf{1 b}$ & 28.0 & 2 & 96 & & 48000 & 2.4 & 52 \\
\hline 13 & $1 b$ & 28.0 & 4 & & 0.21 & 49000 & 2.8 & 76 \\
\hline 14 & $1 \mathbf{b}$ & 112 & 0.7 & 96 & 0.19 & 36000 & 2.2 & 39 \\
\hline 15 & $4 b$ & 112 & 24 & & & & & 0 \\
\hline $16^{d}$ & $\mathbf{2 b}$ & 28.0 & 1 & 95 & & & & 24 \\
\hline $17^{d}$ & $\mathbf{2 b}$ & 28.0 & 2 & 97 & & & & 43 \\
\hline $18^{\mathrm{e}}$ & $\mathbf{2 b}$ & 28.0 & 4 & & 0.24 & 9300 & & 78 \\
\hline $19^{f}$ & $\mathbf{3 b}$ & 28.0 & 12 & 100 & 0.08 & & & 16 \\
\hline
\end{tabular}

${ }^{a}$ Degree of cyclization. ${ }^{b}$ Quoted from ref $5 .{ }^{c}$ Quoted from ref $7 .{ }^{d}$ Degree of cyclization was determined using polymers obtained in the previous work. ${ }^{6}$ Q $Q$ uoted from ref 6. ${ }^{\mathrm{f}}$ Quoted from ref 8.

\section{Measurements}

${ }^{1} \mathrm{H}$ NMR spectra were taken on a JEOL JNM-GX-270 (270 MHz for ${ }^{1} \mathrm{H}$ ) and ${ }^{13} \mathrm{C}$ NMR spectra were measured on a JEOL LA-500 (125 MHz for $\left.{ }^{13} \mathrm{C}\right)$ FT NMR spectrometer using $\mathrm{CDCl}_{3}$ and tetramethylsilane as a solvent and an internal standard, respectively. Size exclusion chromatography (SEC) was performed on a Shimadzu LC-10AD liquid chromatograph equipped with three polystyrene gel columns (Shodex K-804L) and ultraviolet/refractive index dual-detectors using chloroform as eluent. A molecular weight calibration curve was obtained by using standard polystyrene. GC was carried out on a Shimadzu GC-8A gas chromatograph equipped with a silica gel column (Shimadzu DC-11). Viscosity was measured using a Ubbelohde viscometer at $30^{\circ} \mathrm{C}$ in $N, N$-dimethylformamide (DMF).

\section{RESULTS}

\section{Polymerization of 1, 4, and Related Compounds}

The results of the polymerization of $1,4 a$, and $4 b$ are summarized in Table II along with the reported results of $2^{5,6}$ and $3^{7,8}$ that are given for comparison. Both $1 \mathbf{a}$ and $\mathbf{1 b}$ yielded high polymers while no detectable polymer could be obtained from $\mathbf{4 a}$ and $\mathbf{4 b}$, even after prolonged polymerization time. No homopolymerizabilities of the other monoene counterparts of $1, N$-methyl- $N$ (meth)allyl-2-( $t$-butoxycarbonyl)propylamines (5, see Scheme 2), can be reasonably assumed, since it is wellknown that allyl and methallyl compounds have extremely low homopolymerization tendencies. Poly(1) samples are soluble in common solvents, which suggests the formation of highly cyclized polymers. In fact, the degrees of cyclization determined based on ${ }^{1} \mathrm{H}$ NMR spectra were found to be $100 \%$ for poly(1a) and $96 \%$ for poly(1b) (see next section). That the polymerizations were carried out in bulk is indication of how high the cyclization tendency of $\mathbf{1}$ is. These results could be an additional support for the principle for the monomer design for the synthesis of highly cyclized polymers proposed previously. It states that the bifunctional monomers, for which monofunctional counterparts do not polymerize are likely to give rise to highly cyclized polymers, if they polymerize at all. ${ }^{12,13}$

It can be seen from Table II that polymerizations of 1a proceed with almost the same overall polymerization rate as that of $\mathbf{2 a}$. This means that $1 \mathbf{a}$ belongs to a monomer which has high polymerizability, since the monomer $\mathbf{2 a}$ has been reported to be polymerized as rapidly as compounds with $\alpha, \beta$-conjugated double bonds such as $N, N$-disubstituted acrylamides. ${ }^{5}$ This is a typical characteristic that differentiates 1 a from 3a that has considerably lower polymerizability than 2a. Molecular weights and their distribution of $\operatorname{poly}(1 \mathbf{a})$ obtained could not be determined by SEC, since they were not detected under the conditions described in the experimental section. For this reason, viscosities were measured to obtain information on molecular size.

The results of Table II also show that polymerizations of $\mathbf{1 b}$ proceed much more rapidly than $3 \mathrm{~b}$. It polymerizes even faster than $\mathbf{2 b}$. This substituent effect on these methallyl derivatives $(\mathbf{1 b}, \mathbf{2 b}$, and $\mathbf{3 b}$ ) is similar to that observed in the polymerization of the allyl derivatives (1a, 2a, and 3a). Detection of pendant unsaturations in poly $(\mathbf{1 b})$ indicates that the role of the ester $t$-butyl group is less important for enhancing the cyclization tendency than the $N$ - $t$-butyl group, since $\mathbf{2 b}$ yielded completely cyclized polymers. ${ }^{8}$ It can be understood that a bulky ester $t$-butyl group influences the polymerizability of $\mathbf{1}$ in a definitely different manner from an $N$-t-butyl group. Anyhow, the purpose of this investigation to obtain 1,6dienes with not only a high cyclization tendency but also high polymerizability could be achieved by introducing a bulky $t$-butyl group into the ester group.

\section{Pendant Unsaturation of Poly(1)}

The pendant unsaturations which are expected to appear in poly(1) are 6 and 7 shown in Scheme $3 .{ }^{1} \mathrm{H}$ NMR spectra of these polymers are illustrated in Figure 1 along with absorptions due to olefin protons of 1 . The comparison of these spectra clearly shows that poly(1a) 
<smiles>C=C(P)CN(C)CC(C)(CC)C(=O)OC</smiles><smiles>[R]C(C)(CC)CN(C)CC(=C)C(=O)OC(C)(C)C</smiles><smiles>CCC1(P)CN(C)CC1(CC)C(=O)OC</smiles><smiles>[R]C1(C)CN(C)CC(CC)(C(=O)OC(C)=O)C1</smiles>

$\mathrm{R}=\mathrm{H}$ or $\mathrm{CH}_{3}$

Scheme 3.

does not contain practically any pendant unsaturations, while poly(1b) contains a small amount of pendant methallyl groups. Degrees of cyclization of poly(1) listed in Table II were determined based on the signal intensities of methallyl protons detected at around 4.8 ppm and the absorption detected from 0.6 to $3.6 \mathrm{ppm}$.

\section{Repeat Cyclic Unit of Poly(1a)}

Formation of completely cyclized polymers from 1a means that repeating units of poly(1a) consist of either of structures 8 or 9 or the mixture of them. A proton noise decoupled ${ }^{13} \mathrm{C}$ NMR spectrum of $\operatorname{poly}(\mathbf{1 a})$ is illustrated in Figure 2A. DEPT (Distortion Enhancement by Polarization Transfer) measurements of poly(1a) under the conditions where methyl and methine carbons appear upwards and methylene carbons downwards afforded the spectrum shown in Figure 2B. An offresonance decoupled spectrum of $\operatorname{poly}(\mathbf{1 a})$ is illustrated in Figure 2C. Comparison of these spectra allows the assignment of the respective absorption signal of poly(1a) as noted in Figure 2A. The primary carbon observed at $42.4 \mathrm{ppm}$ can be assigned to an $N$-methyl carbon and absorption due to a quaternary carbon detected around $80.5 \mathrm{ppm}$ to that of the ester $t$-butyl carbon based on the reported results for carbons with similar structures. The strong peak of primary carbon recorded at $28.1 \mathrm{ppm}$ could be ascribed to methyl carbons of the $t$-butyl group. The absorptions due to $N$-methyl carbons of pyrrolidine and piperidine rings appear at considerably different chemical shifts. The former are detected at around 42 ppm, while the latter at around $47 \mathrm{ppm}$ as can be seen from the chemical shifts for the $N$-methyl carbons of poly $(\mathbf{2 a})$, poly $(\mathbf{2 b})$, and cyclic model compounds (see Scheme 4) listed in Table III. It is clear that these values do not depend on whether the $N$-methyl carbons are attached to low molecular weight ring structures or to repeat cyclic units of polymers, but on the size of the rings that they are linked to. These results suggest that repeat cyclic units of poly(1a) consist almost exclusively of a five-membered ring.

All the carbons other than $\mathrm{N}-\mathrm{CH}_{3}$ and $\mathrm{C}-\left(\mathrm{CH}_{3}\right)_{3}$ of

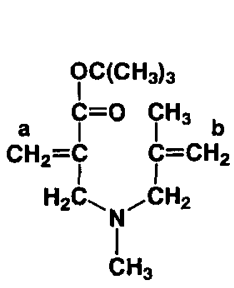

C

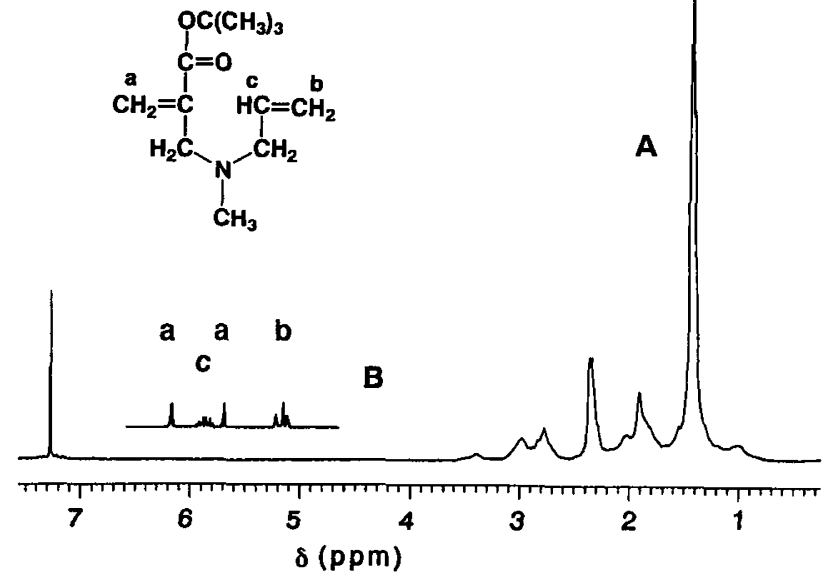

Figure 1. ${ }^{1} \mathrm{H}$ NMR spectra of poly(1) and 1. (A) Poly(1a) (No. 1 in Table II); (B) olefin protons of 1a; (C) poly(1b) (No. 10 in Table II); (D) olefin protons of $\mathbf{1 b}$.

poly $(1 \mathbf{a})$ consist of two peaks, one with strong intensity and the other with weak intensity. Peaks assigned to $N$ methylene carbons are rather complicated but they are considered to consist fundamentally of two strong signals overlapped with two weak signals. This characteristic has been observed in the ${ }^{13} \mathrm{C}$ NMR spectrum of poly(2a), the peak analysis of which has revealed that it consists of two sets of five-membered rings. ${ }^{14}$ The main chain methylene carbons attached to the ring has a trans configuration for one of them and a cis arrangement for the other. The former was found to be a main component. Therefore, ${ }^{13} \mathrm{C}$ NMR spectra of poly(1a) and $\operatorname{poly}(\mathbf{2 a})$ were compared in Figure 3 . There exists fundamental concordance between the two spectral patterns of Figures $3 \mathrm{~A}$ and $3 \mathrm{~B}$ to every detail except for the difference due to ester substituents. Accordingly, the each peak of ${ }^{13} \mathrm{C}$ NMR spectrum of poly(1a) can be assigned as depicted in Figure 3A based on the assignment of ${ }^{13} \mathrm{C}$ NMR spectrum of poly(2a). These spectral analyses are in accordance with those depicted in Figure 2A. This comparison also supports the assignment made above that the poly(1a) contains only five-membered rings as repeat cyclic units. The two sets of absorptions observed for each carbon involved in poly(1a) except for ester and $N$-methyl carbons can be ascribed to trans and cis isomers. The one with stronger intensity in ${ }^{13} \mathrm{C}$ NMR spectrum is attributed to the former and the other with weaker intensity to the latter based on the comparison. 
Table III. ${ }^{13} \mathrm{C}$ NMR chemical shifts of $>N-\mathrm{CH}_{3}$ carbons of various compounds with pyrrolidine and piperidine rings in ppm measured in $\mathrm{CDCl}_{3}$

\begin{tabular}{lccccc}
\hline Compound & poly $(\mathbf{2} \mathbf{a})^{\mathrm{a}}$ & $\mathbf{1 0}^{\mathrm{b}}$ & $\mathbf{1 1}^{\mathrm{b}}$ & ${\text { poly }(\mathbf{2} \mathbf{b})^{\mathrm{c}}}^{\mathbf{1 2}^{\mathrm{b}}}$ \\
\hline Chemical shift & 42.4 & 42.1 & 42.8 & $46.3,46.7$ & $\mathbf{1 3}^{\mathrm{b}}$ \\
\hline
\end{tabular}

${ }^{\mathrm{a}}$ Quoted from ref $14 .{ }^{\mathrm{b}}$ Quoted from ref $15{ }^{\mathrm{c}}$ Quoted from ref 6.

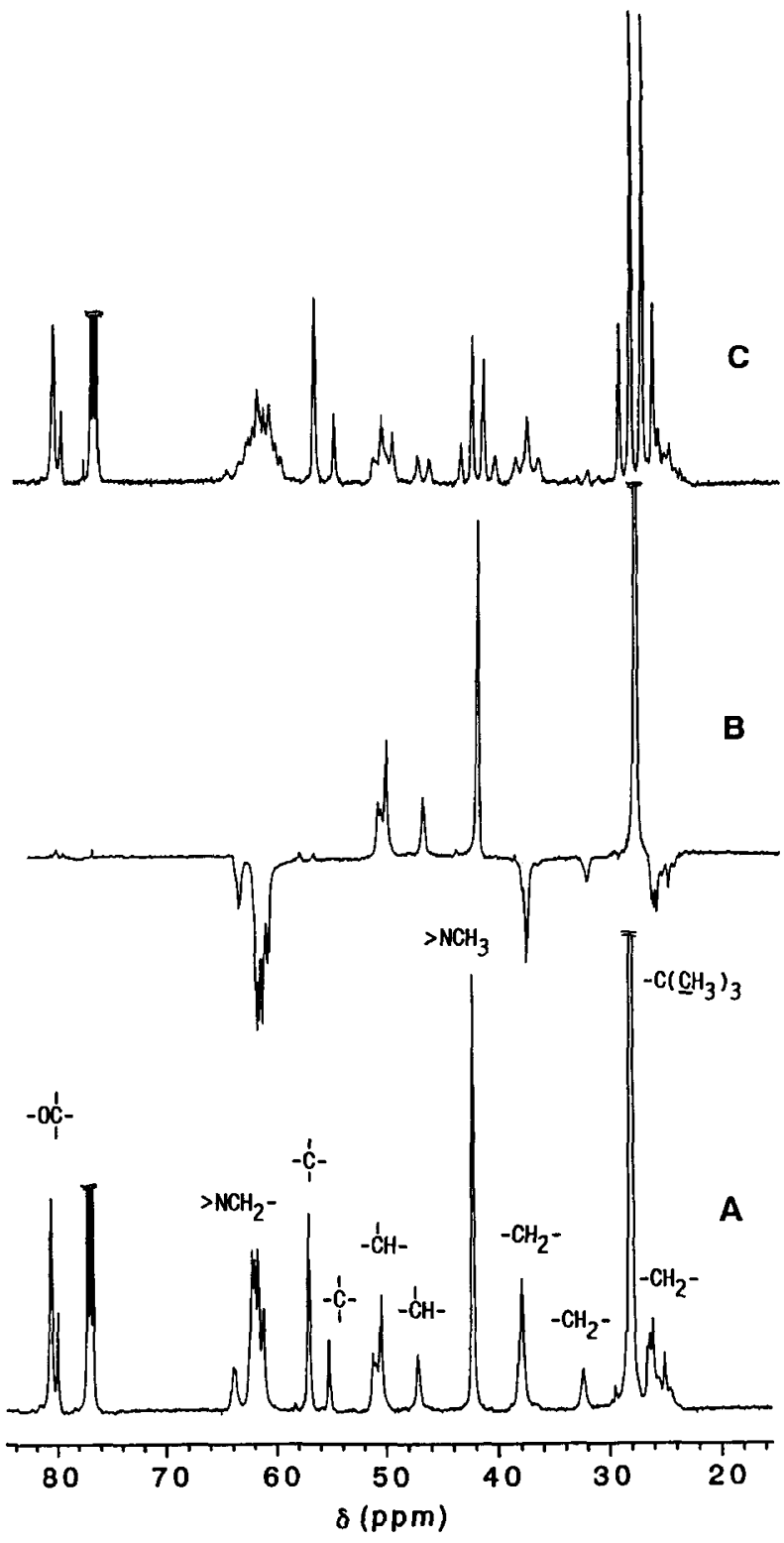

Figure 2. ${ }^{13} \mathrm{C}$ NMR spectra of poly(1a) (No. 2 in Table II). (A) Proton noise decoupled spectrum; (B) DEPT spectrum measured under the conditions where $\mathrm{CH}_{3}$ and $\mathrm{CH}$ carbons are detected upwards and $\mathrm{CH}_{2}$ carbons downwards; (C) off-resonance spectrum.

\section{Repeat Cyclic Unit of Poly(1b)}

A proton noise decoupled ${ }^{13} \mathrm{C}$ NMR spectrum of poly(1b) is illustrated in Figure 4A. DEPT measurements of poly(1b) under the conditions where methyl and methine carbons appear upwards and methylene carbons downwards afforded the spectrum shown in Figure 4B. Since poly $(\mathbf{1 b})$ contains no methine carbon, all the peaks detected in the spectrum of Figure $4 \mathrm{~A}$ can be unambiguously classified into primary, secondary, and quaternary carbons by the DEPT measurement. The peaks due to a<smiles>CCC1CN(C)CC1(CC)C(=O)O[Na]</smiles><smiles>CN1CCCC1</smiles><smiles>CN1CC(C)(C)C(C)(C)C1</smiles><smiles>CCC1(C(=O)OC)CN([13CH3])CC(C)(C)C1</smiles><smiles>CN1CCCCC1</smiles>

12<smiles>CN1CC(C)(C)CC(C)(C)C1</smiles>

Scheme 4.
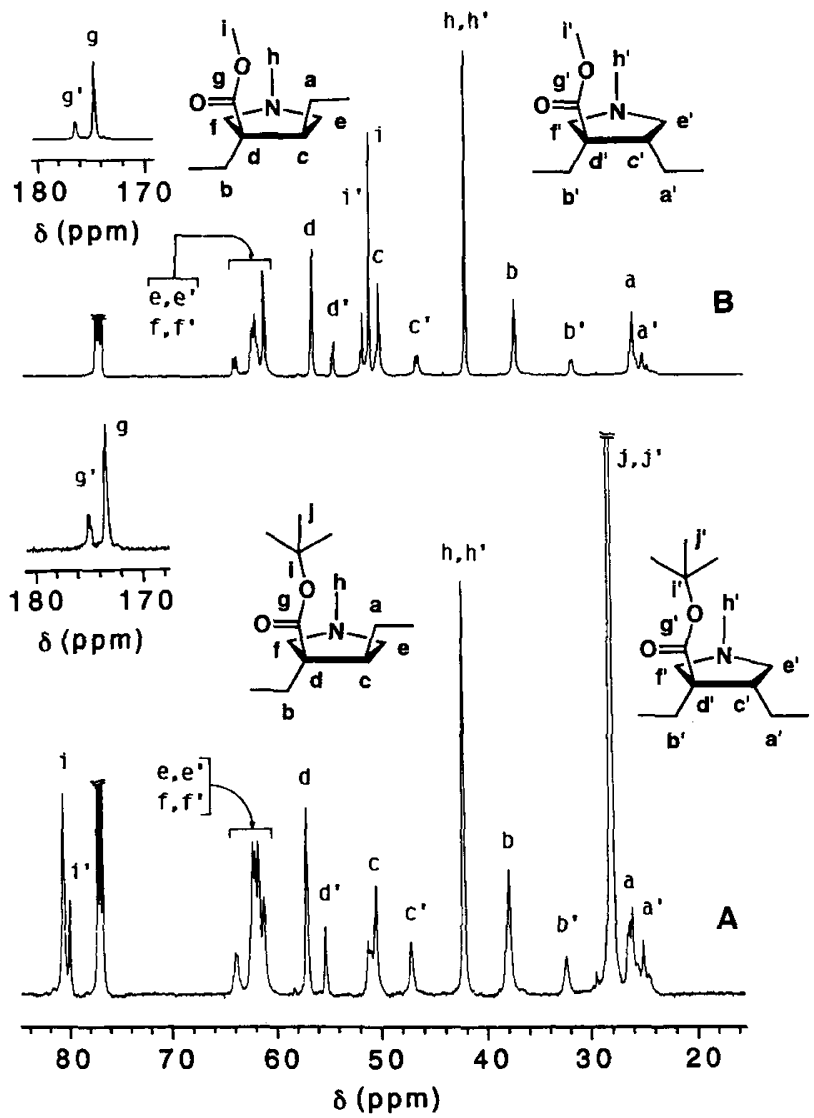

Figure 3. ${ }^{13} \mathrm{C}$ NMR spectra of poly(1a) and poly(2a). (A) Poly(1a) (No. 2 in Table II); (B) poly(2a) (No. 7 in Table II).

primary carbon observed at 46.6 and $47.0 \mathrm{ppm}$ can be assigned to an $N$-methyl carbon and absorption due to a quaternary carbon detected at around $80 \mathrm{ppm}$ to that of the ester $t$-butyl group based on the reported results for carbons with similar structures. The strong peak of primary carbon recorded at $28.1 \mathrm{ppm}$ could be ascribed to 


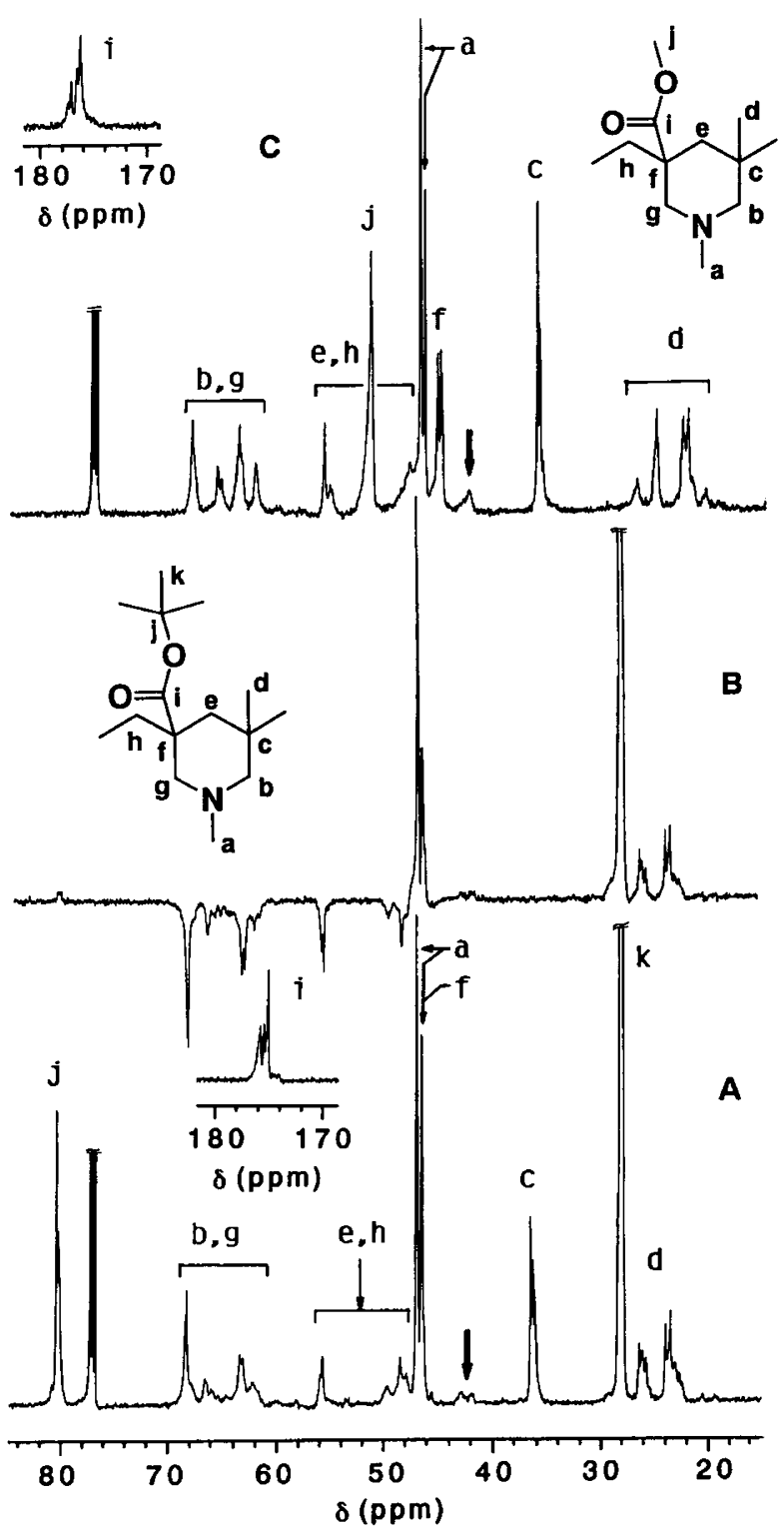

Figure 4. ${ }^{13} \mathrm{C}$ NMR spectra of $\operatorname{poly}(\mathbf{1 b})$ and $\operatorname{poly}(\mathbf{2 b})$. (A) Proton noise decoupled spectrum of poly(1) (No. 12 in Table II); (B) DEPT spectrum of poly $(\mathbf{1 b})$ measured under the conditions where $\mathrm{CH}_{3}$ and $\mathrm{CH}$ carbons are detected upwards and $\mathrm{CH}_{2}$ carbons downwards; (C) proton noise decoupled spectrum of $\operatorname{poly}(\mathbf{2 b})$ (No. 17 in Table II).

methyl carbons of the $t$-butyl group as in the case of poly(1a). Based on the argument made in the previous section, observation of the $N$-methyl carbon at around 47 ppm strongly suggests that poly(1) contains sixmembered rings as repeat cyclic units. Structural studies on poly $(\mathbf{2 b})$ were reported to show that it consists almost exclusively of a six-membered ring as a repeat unit. ${ }^{6}$ Therefore, ${ }^{13} \mathrm{C}$ NMR spectrum of poly $(\mathbf{1 b})$ was compared with that of poly $(\mathbf{2 b})$ in Figure 4 . A characteristic peak which has been attributed to a quaternary carbon, c, of poly $(\mathbf{2 b})$ shown in Scheme 4 is detected at almost the same chemical shift (about $36 \mathrm{ppm}$ ) in poly(1) too. However, a signal due to a carbon, $f$, of poly $(\mathbf{2 b})$ could not be detected in the spectrum of poly $(\mathbf{1 b})$. Other absorption signals which correspond to carbonyl, $>N$ methyl, $>N$-methylene, main chain methylene, and $\mathrm{C}$ methyl carbons, are detected at almost the same chemi-
Table IV. ${ }^{13} \mathrm{C}$ Chemical shifts of $\mathrm{C}_{\beta} \mathrm{H}_{2}=\mathrm{C}_{\alpha}<$ carbons of acryloyl groups of $\mathbf{1}, \mathbf{4 a}, \mathbf{4 b}$, and related compounds in $\mathrm{CDCl}_{13}$

\begin{tabular}{|c|c|c|c|}
\hline \multirow{2}{*}{ Compound } & $\delta_{\mathrm{C}_{\beta}}$ & $\delta_{\mathrm{C}_{\alpha}}$ & $\Delta \delta^{\mathrm{a}}$ \\
\hline & $\mathrm{ppm}$ & ppm & ppm \\
\hline $1 \mathbf{a}$ & 125.5 & 139.4 & 13.9 \\
\hline $4 a$ & 125.2 & 139.6 & 14.4 \\
\hline $2 a^{b}$ & 126.8 & 137.8 & 11.0 \\
\hline $3 \mathbf{a}^{c}$ & 125.7 & 141.1 & 15.4 \\
\hline $\mathbf{1 b}$ & 124.9 & 139.7 & 14.8 \\
\hline $4 b$ & 124.9 & 139.9 & 15.0 \\
\hline $\mathbf{2 b}^{\mathrm{d}}$ & 126.2 & 138.2 & 12.0 \\
\hline $\mathbf{3 b}^{\mathrm{e}}$ & 125.5 & 141.3 & 15.8 \\
\hline MMA $^{\mathbf{f}}$ & 125.5 & 136.3 & 10.8 \\
\hline $\mathbf{1 b}$ & $112.5^{\mathrm{g}}$ & $143.8^{\mathrm{g}}$ & 31.3 \\
\hline
\end{tabular}

${ }^{\mathrm{a}} \delta_{\mathrm{C}_{r}}-\delta_{\mathrm{C}_{\beta} \cdot{ }^{\mathrm{b}} \text { Quoted from ref } 5 .^{\mathrm{c}} \text { Quoted from ref 7. }{ }^{\mathrm{d}} \text { Quoted }}$ from ref $6 .{ }^{\circ}$ Quoted from ref $8 .{ }^{\mathrm{f}}$ Methyl methacrylate. ${ }^{\mathrm{g}}$ Chemical shifts of methallyl carbons.

cal shifts of those of poly(2b), respectively, except for the signals of ester alkyl carbons. This suggests that the absorption due to the carbon, $f$, of poly $(\mathbf{1 b})$ overlaps with one of the signals of $>N$-methyl carbon, the one detected at higher magnetic field. Reduced intensity of the peak when it is recorded by DEPT measurement strongly supports this consideration (compare the spectral pattern of Figure $4 \mathrm{~B}$ with Figure 4A). These considerations lead to the assignment of the respective absorption signal of ${ }^{13} \mathrm{C}$ NMR spectrum of poly $(\mathbf{1 b})$ as shown in Figure 4A. Signal due to a methyl carbon indicated by a thick arrow in Figure $4 \mathrm{C}$ has been tentatively ascribed to $>N$-methyl carbon of five-membered ring, ${ }^{6}$ since it was detected at $42.4 \mathrm{ppm}$. We can also see weak resonance peaks due to a methyl carbon at around $42.4 \mathrm{ppm}$ in the spectrum of Figure 4A (see a thick arrow in the spectrum). Detailed agreement of these spectral characteristics strongly substantiates the conclusion drawn above that poly $(\mathbf{1 b})$ also contains a six-membered ring as a repeat cyclic unit. This is the structural characteristic which differentiates poly(1b) from poly(1a) which contains only fivemembered rings as repeat cyclic units.

\section{NMR Studies of 1 and Related Compounds}

${ }^{13} \mathrm{C}$ Chemical shifts of $\mathrm{C}=\mathrm{C}$ double bonds $\left(\mathrm{C}_{\beta} \mathrm{H}_{2}=\right.$ $\mathrm{C}_{\alpha}<$ ) of the acryloyl groups of $\mathbf{1}, \mathbf{4 a}, \mathbf{4 b}$, and related compounds are summarized in Table IV. Chemical shifts, $\delta_{\mathrm{C}_{\alpha}}$ and $\delta_{\mathrm{C}_{\beta}}$, shift to a higher and a lower magnetic field, respectively, with a linear relationship with increasing electron-attracting power of substituents. ${ }^{16}$ This is because effective conjugation between $\mathrm{C}=\mathrm{C}$ and $\mathrm{C}=\mathrm{O}$ double bonds lowers the electron density on $\mathrm{C}=\mathrm{C}$ double bonds. This means that $\Delta \delta$ obtained by subtracting $\delta_{\mathrm{C}_{\beta}}$ from $\delta_{\mathrm{C}_{\alpha}}$ reflects the influence of substituents more effectively than their respective value. The stronger the electron-attracting power of the substituents, the smaller the value. Comparison of the $\Delta \delta$ values of $\mathbf{1}$ and 2 with those of $\mathbf{3}, \mathbf{4 a}, \mathbf{4 b}$, and methyl methacrylate (MMA) indicates that the ester $t$-butyl groups interfere with the conjugation between olefin and carbonyl double bonds in these compounds as much as the $N$ - $t$-butyl group. Coplanarity of these double bonds is considered to be distorted probably due to steric strain caused by bulky substituents. However, the conjugation of the acryloyl groups of $\mathbf{1}$ and $\mathbf{2}$ is considerably effective even in $t$-butyl derivatives, judging from $\Delta \delta$ of these com- 
pounds and methallyl carbons of $\mathbf{1 b}$. Similar dependence of $\Delta \delta$ on substituents was also observed in a series of ether dimers of $\alpha$-(hydroxymethyl)acrylic acid esters. ${ }^{9,17}$

\section{DISCUSSION}

One of the characteristic features observed in the cyclopolymerizations of $\mathbf{1}$ is that they polymerize rapidly despite the fact that their $\alpha$-substituted acryloyl groups conjugate less effectively than those of 2 . This observation is rather different from that observed in the cyclopolymerizations of $\mathbf{3 a}$ and $\mathbf{3 b}$. The $N$-t -butyl group of these monomers interferes with the effective conjugation of their acryloyl groups. Accordingly, $\mathbf{3 a}$ and $\mathbf{3 b}$ polymerize fairly slowly as compared with $\mathbf{2 a}$ and $\mathbf{2 b}$, respectively. ${ }^{5-8} \Delta \delta$ Values shown in Table IV indicates that ester- and $N$ - $t$-butyl groups reduce the conjugative nature of the $\alpha$-substituted acryloyl groups of 1 and 3 to the same extent. Nevertheless, $1 \mathbf{a}$ and $\mathbf{1 b}$ polymerize much more rapidly than $\mathbf{3 a}$ and $\mathbf{3 b}$, respectively. Polymerizations of $\mathbf{1 b}$ proceed even faster than $\mathbf{2 b}$. Such an acceleration of polymerizations by a bulky substituent has been observed in other monomers such as fumarates, ${ }^{1}$ methacrylates, ${ }^{2}$ and ether dimers of $\alpha$-hydroxymethyl acrylates. ${ }^{9}$ Those with a bulky ester group polymerized much faster than those with a smaller one such as a methyl group. This polymerization behavior was interpreted by assuming that steric hindrance caused by a bulky substituent reduces more extensively the termination reaction rate than the propagation reaction rate. ${ }^{1,2,9}$ Substituent effect observed in the present investigation could be explained in a similar manner.

Another characteristic effect of the ester $t$-butyl group on the polymerizations of these dienes is that it does not influence entirely the structure of the repeat cyclic units of their polymers different from the $N$-t-butyl group. Poly $(\mathbf{2 b})$ consists almost exclusively of six-membered rings as repeat cyclic units, ${ }^{6}$ while poly $(\mathbf{3 b})$ contains a considerable amount of five-membered rings. ${ }^{8}$ Structural studies showed that poly $(\mathbf{1 b})$ consist exclusively of six-membered rings like poly $(\mathbf{2 b})$. We have reported that $N$-phenyl- $N$-methallyl-2-(methoxycarbonyl)allylamine, a compound with an $N$-phenyl group instead of an $N$ methyl group of $\mathbf{2 b}$, also yields polymers that contain a considerable amount of five-membered rings along with six-membered rings. ${ }^{8}$ This suggests that bulky $N$ substituents narrow the bond angles between the two $\mathrm{CH}_{2}-\mathrm{N}$ linkages of the $-\mathrm{CH}_{2}-\mathrm{N}-\mathrm{CH}_{2}-$ group to favor five-membered ring formation. In the case of $\mathbf{2 a}$ and $\mathbf{3 a}$, polymers that consist exclusively of five-membered rings are formed irrespective of their $N$-substituents. ${ }^{14}$ It was found that 1a also yields polymers with five-membered rings as repeat cyclic units. We have already shown that a substituent on an olefinic double bond of these dienes tends to favor six-membered ring formation. ${ }^{6,8,14}$ In agreement with the observation, $\mathbf{1 b}$ formed six-membered rings as repeat cyclic units and 1a five-membered rings.

The degree of cyclization detected for $\operatorname{poly}(\mathbf{1 b})$ is almost the same as that observed for $\operatorname{poly}(\mathbf{2 b})$, while $\mathbf{3 b}$ yielded completely cyclized polymers (see Table II). ${ }^{8}$ This shows that the bulky ester $t$-butyl group does not work effectively for enhancing the cyclization tendency. In the case of ether dimers of $\alpha$-hydroxymethyl acrylates, cyclization tendencies of these dienes increased with the bulkiness of ester alkyl groups. ${ }^{9}$ The extent was, however, small. It can be understood that introduction of a bulky substituent to a proper position is essential to enhance cyclization tendency.

\section{CONCLUSIONS}

A bulky alkoxy group of $N$-substituted $N$-(meth)allyl2-(alkoxycarbonyl)allylamines enhances their overall polymerization rates, though it reduces the conjugative nature between the $\mathrm{C}=\mathrm{C}$ and $\mathrm{C}=\mathrm{O}$ double bonds of their $\alpha$-substituted acryloyl groups. This polymerization behavior was interpreted by assuming that steric hindrance caused by the bulky substituent reduces more extensively the termination reaction rate than the propagation reaction rate. The bulky alkoxy group does not influence the cyclization tendency of these monomers and the structure of the repeat cyclic units of the polymers derived therefrom.

These effects of the bulky ester group are entirely different from those of a bulky $N$-substituent. The latter reduces the polymerizability, enhances the cyclization tendency, and changes the structure of the repeat cyclic units. $^{6-8}$

Acknowledgment. This work was supported partly by a Grant-in-Aid for Scientific Research (C) (No. 10650864) from the Ministry of Education, Science and Culture of Japan, for which we are grateful.

\section{REFERENCES}

1. T. Otsu, T. Yasuhara, and A. Matsumoto, J. Macromol. Sci. Chem., A25, 537 (1988).

2. A. Matsumoto, A. Tanaka, and T. Otsu, Macromolecules, 24, 4017 (1991).

3. W. Fukuda, Y. Suzuki, and H. Kakiuchi, J. Polym. Sci., Polym. Lett. Ed., 26, 305 (1988).

4. T. Kodaira, M. Okumura, M. Urushisaki, and K. Isa, J. Polym. Sci. Part A: Polym. Chem., 31, 169 (1993).

5. T. Kodaira, T. Fujisawa, Q. Q. Liu, and M. Urushisaki, Macromolecules, $\mathbf{2 9}, 484$ (1996).

6. T. Kodaira, N. Kasajima, and M. Urushisaki, Polymer, 41, 2831 (2000).

7. T. Kodaira, Q. Q. Liu, and M. Urushisaki, Polym. J., 28, 1000 (1996).

8. T. Kodaira, M. Urushisaki, and N. Kasajima, Polym. J., 32, $140(2000)$.

9. T. Tsuda and L. J. Mathias, Polymer, 35, 3317(1994).

10. J. Villieras and M. Rambaud, Synthesis, 924(1982).

11. A. L. Morrison and H. Rinderknecht, J. Chem. Soc., 1478 (1950).

12. T. Kodaira and F. Aoyama, J. Polym. Sci., Polym. Chem. Ed., 12, 897 (1974)

13. T. Kodaira, in "The Polymeric Materials Encyclopedia", J. C. Salamone, Ed., CRC Press, Inc., Boca Raton, FL, 1996, p 1750.

14. T. Kodaira, Q. Q. Liu, M. Satoyama, M. Urushisaki, and H. Utsumi, Polymer, 40,6948 (1999).

15. D. G. Hawthorne, S. R. Johnes, and R. I. Willing, Aust. J. Chem., 29, 315 (1976).

16. K. Hatada, K. Nagata, and H. Yuki, Bull. Chem. Soc. Jpn., 43, 3267 (1970).

17. J. W. Stansbury, Macromolecules, 24, 2029 (1991). 